\title{
Investigation Of Methods To Reduce The Micro Hardness Of Marble Aggregates
}

\author{
YusupovKhamzaIbadovich $^{a}$, IrodaNazarbaevnaSalimovab ${ }^{b}$ DildoraNazarbaevna Djalolova \\ a Professor department "Construction technology" at Tashkent institute of architecture and civil engineering, Tashkent, \\ Uzbekistan \\ ${ }^{\mathbf{b}} \mathrm{PhD}$ doctorate at Tashkent institute of architecture and civil engineering, Tashkent,Uzbekistan \\ ${ }^{\mathbf{c}}$ Senior lecturer at Tashkent institute of architecture and civil engineering, Tashkent,Uzbekistan
}

Article History: Received: 10 November 2020; Revised 12 January 2021 Accepted: 27 January 2021; Published online: 5 April 2021

\begin{abstract}
This research paper describes the surface degradation properties of brittle and plastic-brittle materials like marble, crumbling body properties, load acceleration parameters and effects associated with the environment in which grinding is performed. When applied to marble filler in mosaic coatings, first of all, abrasive erosion occurs and a large number of cemented abrasive grain surfaces are removed by means of grinding binders, i.e. a micro-scratch process.
\end{abstract}

Keywords: Abrasion, marble, microcracks, filler, microhardness, restoration methods, research

\section{Introduction}

For the mosaic coating of the floor, more as shown above, marble crushed stone slabs are used.Full crystalline marble and marbled limestone are used in the construction. Marbled limestones will be bleached and are rocks during the transition from limestone to true marble.

There are dozens of marble deposits in Uzbekistan and elsewhere, from which marble slabs with a crushing strength limit of 6 to $12 \mathrm{kPa}$ are extracted for construction. The main rock in marble is the mineral calcium, the content of which varies from 85 to $89.8 \%$.

Four marble quarries were used as raw materials in the study of marble grinding, from which marble pellets were mainly supplied to construction organizations. The physical and mechanical properties of marbles in these deposits are given in Table 1. The data in this table are based on the average values of the five samples taken from each field. The experiment was conducted mainly using marble from the Almalyk deposit. Data from other fields were obtained on the basis of analysis from various technical literature.

Table 1. The main physical, mechanical and decorative properties of the studied marble rocks

\begin{tabular}{|c|c|c|c|c|c|c|c|}
\hline № & Miningsite & $\begin{array}{c}\text { The color of } \\
\text { the rock }\end{array}$ & $\begin{array}{c}\text { Densi } \\
\mathbf{t y , g / s} \\
\mathbf{m}^{\mathbf{3}}\end{array}$ & $\begin{array}{c}\text { Volumetr } \\
\mathbf{i c} \text { mass, } \\
\mathbf{g} / \mathbf{s m}^{\mathbf{3}}\end{array}$ & $\begin{array}{c}\text { The limit } \\
\text { of mus- } \\
\text { strength in } \\
\text { crushing, } \\
\mathbf{k P a}\end{array}$ & $\begin{array}{c}\text { Microhar } \\
\mathbf{d n e s s ,} \\
\mathbf{H} / \mathbf{m m}^{\mathbf{2}}\end{array}$ & $\begin{array}{c}\text { Porosit } \\
\mathbf{y}, \mathbf{\%}\end{array}$ \\
\hline 1 & $\begin{array}{c}\text { Almalyk } \\
\text { (Uzbekistan) }\end{array}$ & $\begin{array}{c}\text { White with a } \\
\text { yellow tint }\end{array}$ & 2,7 & 2,64 & 6,47 & 149,2 & 1,7 \\
\hline 2 & $\begin{array}{c}\text { Koelgin (Ural- } \\
\text { Russia) }\end{array}$ & Whitecolor & 2,71 & 2,68 & 6,53 & 144,3 & 1,1 \\
\hline 3 & $\begin{array}{c}\text { Ufaley } \\
\text { (Chelyabinsk- } \\
\text { Russia) }\end{array}$ & Blue-brown & 2,75 & 2,7 & 10,79 & 159,7 & 1,72 \\
\hline & $\begin{array}{c}\text { Stepanakert } \\
\text { (Armenia) }\end{array}$ & Reddishbrown & 2,72 & 2,7 & 12,46 & 172,8 & 1,00 \\
\hline
\end{tabular}

The data of the technical literature in this field and the analysis of specially conducted experimental studies allowed to obtain the initial evidence needed to assess the intensity of the grinding process of abrasive-bonded marbles (Table 2). Based on the data obtained, it was determined that the intensity of the process of grinding marbles depends on their microhardness, the characteristics of the abrasive elements and other parameters: 


$$
\tau=\frac{Q_{m}}{1,76 K_{1} K_{2} V\left(q_{a} / H_{m}\right)^{\alpha}},{ }_{\text {here }}
$$

$\tau$ - grinding time, minutes; $\quad Q_{m}$ - cutting depth, mm;

$K_{1}$ - coefficient depending on the type of marble;

$\kappa_{2} ; \alpha$ - coefficients depending on the description of the abrasive elements.

$\mathrm{K}_{2}=\frac{S_{1}}{S_{2}} \cdot h_{\max }^{2} \cdot C\left(\frac{1}{B}\right)^{\alpha} \cdot Z ; \alpha=\frac{2}{v}$,

$v$ - grinding speed, $\mathrm{mm} / \mathrm{min}$;

$\mathrm{q}_{\mathrm{a}}$ - the relative pressure of the abrasive elements on the marble surface, $\mathrm{H} / \mathrm{mm}^{2}$;

$\mathrm{h}_{\mathrm{M}}$ - microhardness of marble, $\mathrm{H} / \mathrm{mm}^{2}$;

$\mathrm{S}_{1}-$ the working area of the abrasive element of the grinding machine, $\mathrm{mm}^{2}$;

$\mathrm{S}_{2}$ - grinding area per turn of the traverse, $\mathrm{mm}^{2}$;

$\mathrm{H}_{\max }$ - the maximum height of the unevenness of the abrasive grains, $\mathrm{mm}$;

$\mathrm{C}$ - the number of cutting grains on the surface of the abrasive element, $\mathrm{pcs} / \mathrm{mm}^{2}$;

$B, v$ - base curve parameters

$$
\text { в }=1 \div 6 ; \quad v=0,5 \div 2 \text {; }
$$

$\mathrm{Z}$ - number of abrasive elements, pcs;

$\mathrm{K}_{1}, \mathrm{~K}_{2}$ and $\alpha$ - the coefficients retain constant values for a particular type of marble and type of abrasive element.

The reliability of the formula was confirmed by comparing theoretical and experimental data obtained in grinding marbles (Fig. 1).

It can be seen from the formula that the grinding time decreases with increasing grinding speed and relative pressure and increases with increasing microhardness of marble.

But as the speed and relative pressure increase, the energy consumption increases dramatically. The most expedient way to reduce the microhardness of marble in the pre-fracture area is to apply ithe device does not increase the grinding process energy costs.

\begin{tabular}{|c|c|c|c|}
\hline Name of values & $\begin{array}{l}\text { An accounting formula or } \\
\text { symbol }\end{array}$ & $\begin{array}{c}\text { Unitofmeas } \\
\text { urement }\end{array}$ & Note \\
\hline 1 & 2 & $\mathbf{3}$ & 4 \\
\hline $\begin{array}{l}\text { The ratio of the depth of the } \\
\text { groove to the width of the } \\
\text { groove, leaving a single } \\
\text { piece of abrasive element in } \\
\text { the marble }\end{array}$ & $\kappa_{1}$ & - & $\begin{array}{l}K_{1}=4,5 \div 6 \\
\text { depending on the micro- } \\
\text { hardness of the marble }\end{array}$ \\
\hline $\begin{array}{l}\text { The average length of the } \\
\text { corridor }\end{array}$ & $\ell=7,03 R=\ell_{i p m} \cdot 2 \pi R$ & $\mathrm{~mm}$ & $\begin{array}{l}\quad \ell_{\check{y p m}}=1,12 \\
\mathrm{R}-\text { grinding machine plate } \\
\text { radius, mm }\end{array}$ \\
\hline $\begin{array}{l}\text { Maximum depth of the } \\
\text { corridor }\end{array}$ & $t_{\max }^{2}=\left(\frac{q_{a}}{b H_{\mu}}\right)^{\frac{2}{v}} \cdot h_{\max }^{2}$ & $\mathrm{~mm}$ & $\begin{array}{l}\mathrm{b}, \quad v-\text { base curvature } \\
\text { parameters; } v=0,5 \div 2 ; \mathrm{b}=1 \div 6 \\
\mathrm{~h}_{\max }-\text { the maximum height } \\
\text { of the abrasive grain } \\
\text { roughness }\end{array}$ \\
\hline
\end{tabular}

Table 2.Preliminary data for estimating the intensity of the marble grinding process on the basis of microhardness 


\begin{tabular}{|c|c|c|c|}
\hline $\begin{array}{l}\text { Working area of the abrasive } \\
\text { element of the grinding } \\
\text { machine }\end{array}$ & $\mathrm{S}_{1}$ & $\mathrm{~mm}^{2}$ & - \\
\hline $\begin{array}{l}\text { The number of turns of the } \\
\text { traverses of the machine }\end{array}$ & $\mathrm{N}$ & cycle/min & - \\
\hline Grindingspeed & $v$ & $\mathrm{~mm} / \mathrm{min}$ & $v=n \cdot R$ \\
\hline $\begin{array}{c}\text { The number of grains cut on } \\
\text { the surface of the abrasive } \\
\text { element }\end{array}$ & $\mathrm{C}$ & piece $/ \mathrm{mm}^{2}$ & Accordingtothereferences \\
\hline Numberofabrasiveelements & $\mathrm{Z}$ & piece & - \\
\hline $\begin{array}{l}\text { Relative cutting of marble in } \\
\text { grinding }\end{array}$ & $Q_{y}=\frac{1}{4} \cdot K_{1} l \cdot t_{\max }^{2} \cdot S_{1} \cdot C \cdot n$ & $\mathrm{Mм}^{3} /$ мин & - \\
\hline Depth of cut in one minute & $Q_{M}=\frac{Q_{y}}{Q_{z}}$ & $\mathrm{~mm} / \mathrm{min}$ & $\begin{array}{l}\mathrm{S}_{2}-\text { the grinding area of the } \\
\text { traverse in one turn, } \mathrm{mm}^{2} \mathrm{~S}_{2} \\
=\left[R^{2}-\left(R-\frac{d}{2}\right)^{2}\right]\end{array}$ \\
\hline $\begin{array}{l}\text { Conditional diameter of the } \\
\text { abrasive element }\end{array}$ & D & $\mathrm{mm}$ & - \\
\hline
\end{tabular}

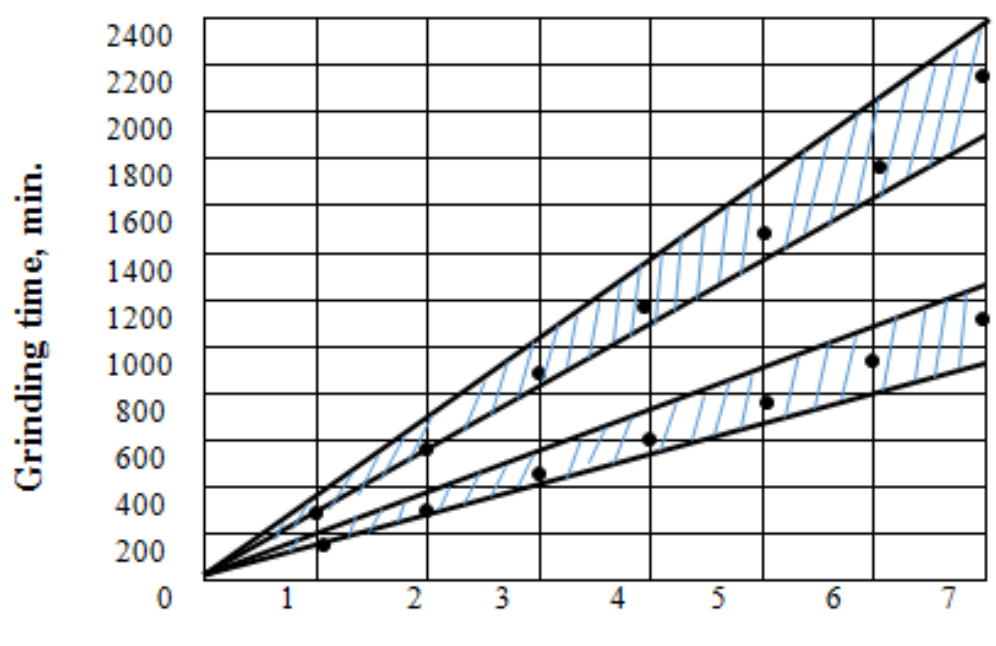

Removable layer, mm

Figure 1.Comparison of experimental and theoretical data on the grinding speed of marble.

Barcodes in the drawing - the zone of theoretical calculations;

The points in the drawing are experimental data applied to abrasive elements of type $\mathrm{KCh}-40-\mathrm{S}_{1}-\mathrm{B}$.

1. Marble with a hardness of $\mathrm{H}_{\mathrm{m}}=172,8 \mathrm{H} / \mathrm{mm}^{2}$;

2. Marble with a hardness of $\mathrm{H}_{\mathrm{m}}=142,0 \mathrm{H} / \mathrm{mm}^{2}$.

Study of possible ways to reduce the microhardness of a marble aggregate in grinding has shown that the highest efficiency is achieved in the presence of surfactants (PS).

Based on the initial research work, it was possible to develop an improved method and technology of grinding mosaic flooring using surfactants. 
In determining the grinding time of the mosaic coating, the marble pattern-slabs were first sanded to create the same roughness before testing. The results of the measured values depending on the thickness of the layer to be extracted during the grinding of marbles in different mineral deposits are given in Table 3 .

Table 3. Grinding time of marbles, in minutes

\begin{tabular}{|c|c|c|c|c|c|c|c|c|}
\hline \multirow{2}{*}{ Miningsite } & \multicolumn{8}{|c|}{ The total thickness of the obtained layers, mm } \\
\cline { 2 - 8 } & $\mathbf{0 , 5}$ & $\mathbf{1}$ & $\mathbf{2}$ & $\mathbf{3}$ & $\mathbf{4}$ & $\mathbf{5}$ & $\mathbf{6}$ & $\mathbf{7}$ \\
\hline Almalyk & 99, & 19 & 39 & 59 & 792, & 989, & 1187, & 1386 \\
(Uzbekistan) & 3 & 8,0 & 5,6 & 4,3 & 5 & 6 & 3 &, 1 \\
\hline Koelgin (Ural- & 80, & 16 & 31 & 47 & 541, & 701, & 859,1 & 1019 \\
Russia) & 1 & 0,6 & 9,8 & 9,1 & 3 & 5 &, 4 \\
\hline Ufaley & 12 & 24 & 49 & 74 & 999, & 1248 & 1498, & 1749 \\
(Chelyabinsk-Russia) & 5,0 & 9,5 & 9,7 & 9,3 & 1 &, 6 & 9 &, 1 \\
\hline Stepanakert & 15 & 29 & 60 & 90 & 1201 & 1509 & 1812, & 2103 \\
(Armenia) & 0,2 & 8,9 & 1,3 & 0,6 &, 3 &, 1 & 0 &, 5 \\
\hline
\end{tabular}

The analysis of the data in Table 3 shows that if a layer of marble is sanded to a thickness of $7 \mathrm{~mm}$, the cement stone will be sanded 2.5 to 4.5 times slower than in 14 days. In addition, marbles in different deposits are polished differently.

It is easier to grind marble in the Koelgin deposit, where the value of the crushing strength is higher than that of the marble from the Almalyk deposit, but its hardness is low.

This situation can be explained by the fact that the strength of marble depends not only on its mineralogical composition (percentage of calcite) and structure, but also on the presence of microcracks in different layers of the marble body, which to a lesser extent affects grinding.

The smoothness of mosaic coatings was studied with fractions of 2.5 - 5, 5-10 and $10-15 \mathrm{~mm}$ in one mass fraction of gray portland cement and three mass fractions of marble.

Only marble from the Almalyk deposit was used for the experiment. Data on the remaining marble deposits are taken from the technical literature.

Marble chips were obtained by grinding slabs learned in sanding marble. For each series of the test, three sample-boards were prepared and stored under the same conditions as the samples made of cement stone.

Samples were inspected every 5 and 14 days after the solidification period. Samples from the marble slabs of the Almalyk deposit were tested over a 7-day period to determine the extent to which the results changed between the specified storage periods.

Figure 2 shows curvilinear graphs of the grinding speed of a mosaic cladding constructed of marble slabs from different deposits. Graphs were constructed based on the average values of the three samples. As can be seen from the graphs, the position of the curves appears to be similar to the change in cement stone grinding time. The surface layer of the mosaic coating is removed faster than the base, as this layer is mainly composed of cement stone.

The smoothness of the coating is highly dependent on the age of the cement stone.

The graphs in Figure 3 show the curves of the time taken to obtain a seven-millimeter layer of marble-coated mosaic coating and cement stone from the Almalyk deposit. This takes into account the dependence of the shelf life of the specimens under normative conditions. The characteristics of the curves show that increasing the age of the mosaic coating from 5 to 14 days results in a sharp increase in its grinding time. When the coating is stored for more than 14 days, the time consumption increases insignificantly, as the future strength and hardness of the cement stone in crushing will increase much more slowly than in the initial period.

A more interesting result is known when comparing the grinding time of mosaic flooring at different ages with the grinding times of cement stone and marble in different deposits.

It is known that the time required to obtain a $7 \mathrm{~mm}$ thick mosaic coating, i.e. when there is an average saturation level of $60-70 \%$ of the marble surface, is relatively low in obtaining a layer of marble of such thickness. At the same time, compared to the marble surface was spent almost 15 times less for 5-day flooring, 6 times for 7day and 3 times less for 14-day. 
To determine the cause of this condition, profilograms were obtained from 5, 7, and 14-day-old mosaic coating samples from polished surfaces to a thickness of 3-5 mm. Profilograms were obtained on a profilographprofilometer instrument "Caliber - VEI" according to the following methodology. On the surface of the samples is placed a mark (groove line) at the beginning and end of a conditionally straight line of 3-5 cm, which passes along the filler grain and cement stone.
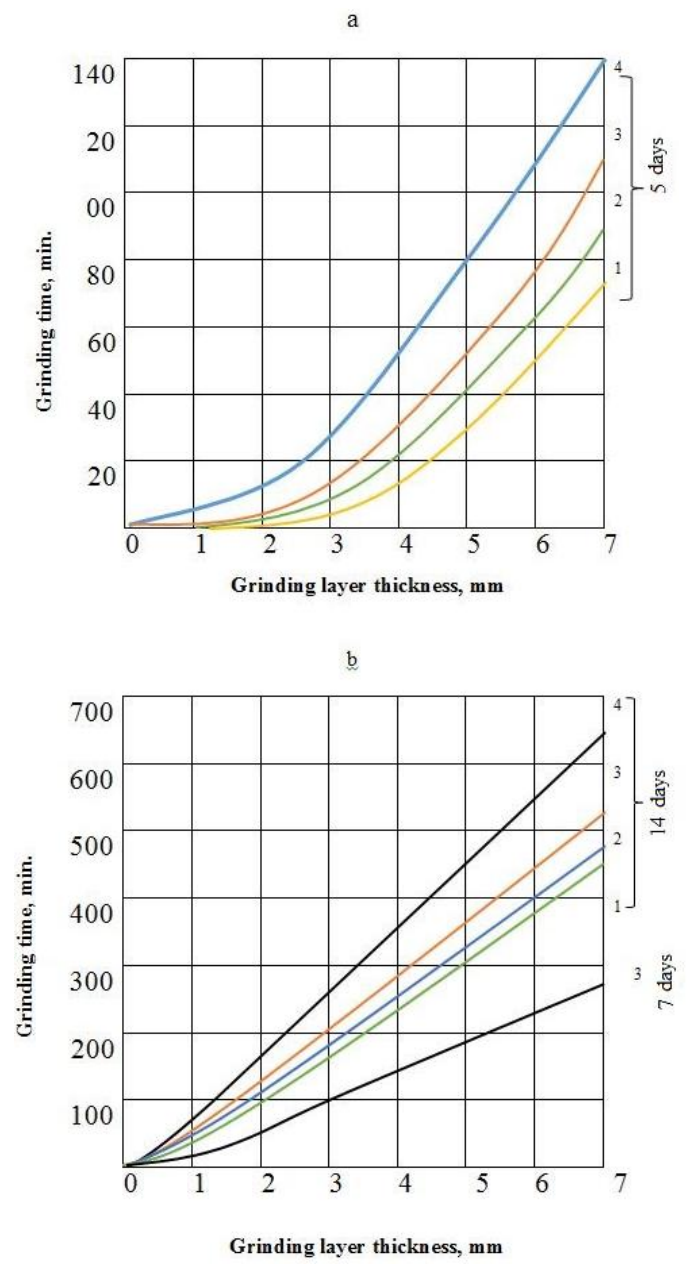

Figure 2. Grinding of marble-coated mosaic flooring from various excavations

a - 5-day flooring; b - 7 and 14 day flooring.

1 - Marble fragments from the Koelgin (Ural-Russia) deposit;

2 - Marble fragments from the Almalyk (Uzbekistan) deposit;

3 - marble fragments from the Ufaley (Chelyabinsk-Russia) Deposit;

4 - Marble fragments from the Stepnokert (Armenia) deposit. 


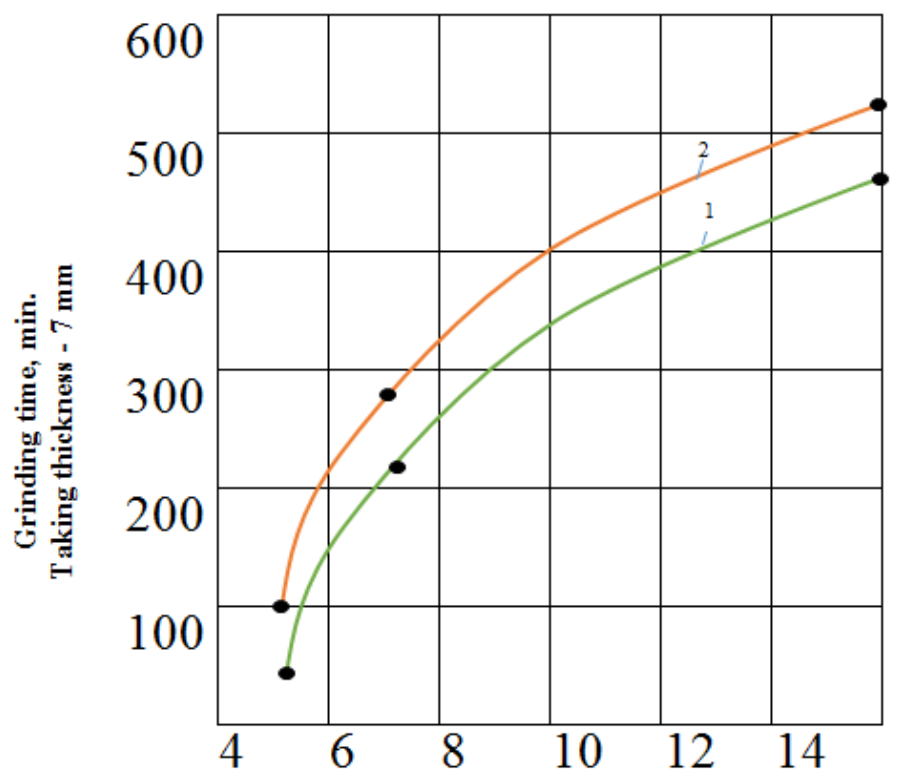

Samples age, day

Figure 3. The relationship between the age of grinding and the age of the mosaic coating and cement stones with marble fragments from the Almalyk deposit.

1 - cement stone; 2 - Mosaic floor with marble slabs from Almalyk deposit.

Note: The thickness of the removable grinding layer is assumed to be $7 \mathrm{~mm}$.

A steel ruler is placed over the groove line and a needle sensor slides from its edge. The needle prints on the surface of the sample, and its cross-section (profile) is automatically recorded on a special tape by magnifying it 1000 times vertically and 20 times horizontally.

Figures $4 \mathrm{a}, \mathrm{b}$, and $\mathrm{c}$ show the most important parts of the profilogram parts at the boundary between the marble and the cement stone.

Analysis of the profilograms showed that the profile properties of the mosaic coatings at 5,7 and 14 days were similar.

The surface of the marble aggregate protrudes from the surface of the cement stone. The difference in surface levels varies within the range of 30-40 microns. Consequently, it can be assumed that during the grinding process, the cement stone eats faster, stripping off the remaining grain of the filler. In this case, the abrasive stone binds directly to the surface of the filler particles and presses the pulverized product (sludge) into the grooves formed in the body of the cement stone. The formation of grooves leads to a sharp increase in the relative pressure on the marble aggregates and facilitates the grinding process. This results in rapid erosion of the marble.

The sludge helps in the erosion of the cement stone at this time. Abrasive is a sludge in gravel printed with stone, which in turn is abrasive to cement stone as a fine particle of marble. All these phenomena lead to the fact that the time required to grind the mosaic coating is much lower than to grind the marble.

It is known that the analysis of profiles shows that the surface of the aggregate grain rises 30-40 microns above the surface of the cement stone. This

means that the relative pressure from the abrasive elements of the grinding machines in grinding affects virtually only the marble filler, not the entire area of the mosaic coating placed under the elements, as in the grinding of homogeneous objects. This creates increased pressure on the filler grains and dramatically increases the intensity of mosaic coating removal. In this case, the cement stone is sanded with a free abrasive. This abrasive role is performed by marble, the decay product of cement stone and crushed grains of abrasive elements, and their mixture with water is called sludge. 
The identified features of the mosaic coating grinding process and a special case have been identified for future research in the direction of studying the effect of various technological factors on the intensity of the marble grinding process associated with abrasives.

In a special case, the filler (marble) has the main effect on the rapid removal of the coating to start grinding the cement stone at a reasonable strength (hardness).

Cement stone

$\mathrm{MM}$

0,06

0,05

0,04

0,03

0,02

0,01

0,00

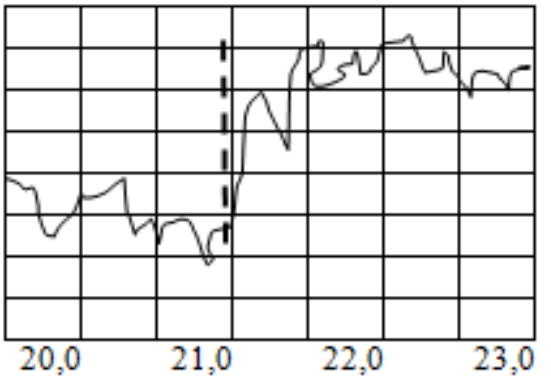

Marble

Cement stone

Marble

MM

0,09

0,08

0,07

0,06

0,05

0,04

0,03

0,02

0,01

0,00

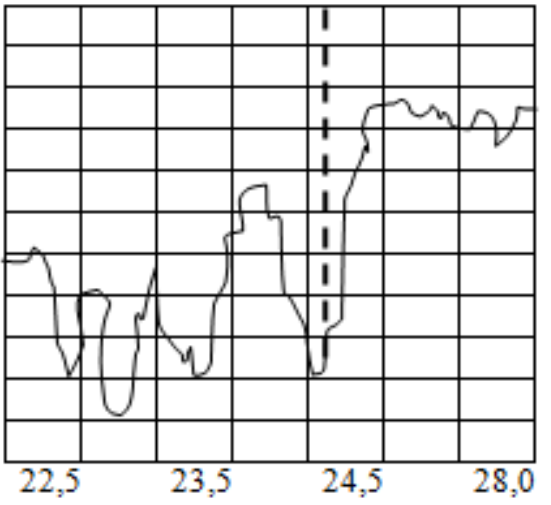

Cement stone

Marble

MM

0,09

0,08

0,07

0,06

0,05

0,04

0,03

0,02

0,01

0,00

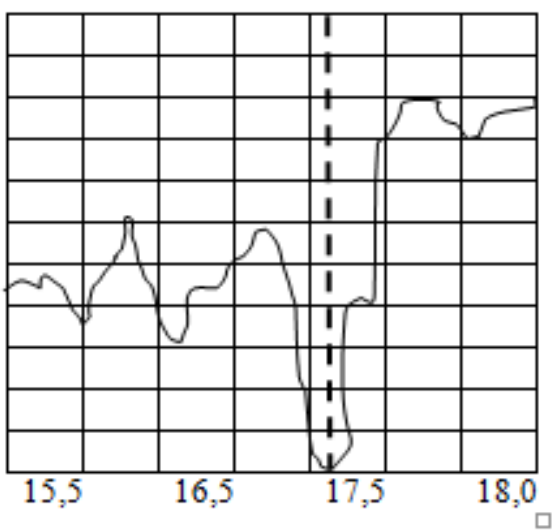

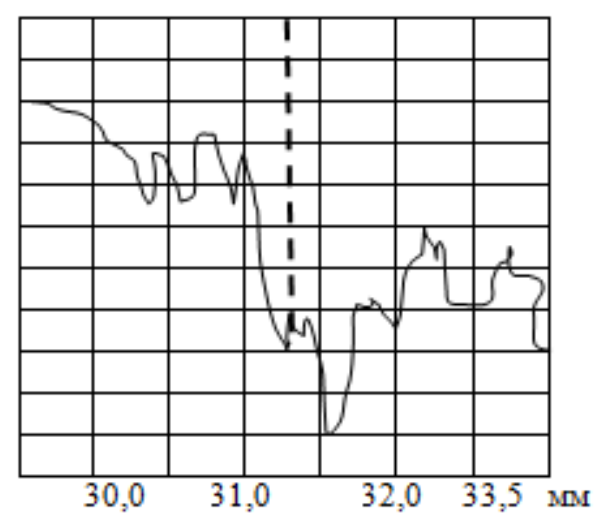

c

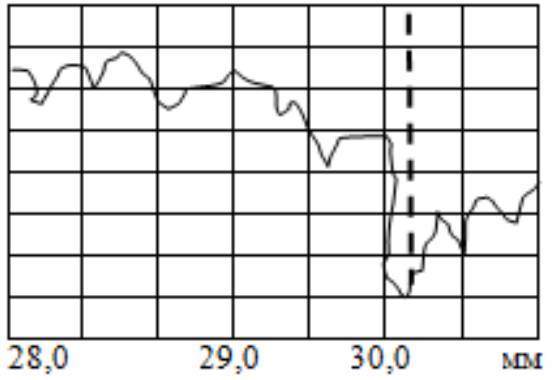

a

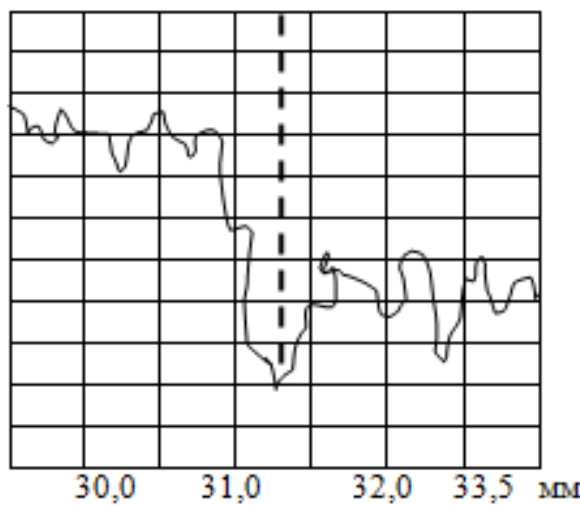

b

\section{Ceent stone}

Cement stone

Cement stone

Figures4.a, b and c. Profilograms of the mosaic cladding at the boundary between the marble and the cement stone. 
$\mathrm{a}$ - at the age of 5 days; $\mathrm{b}$ - at the age of 7 days; $\mathrm{c}$ - 14 days old.

\section{Conclusion}

The surface degradation properties of brittle and plastic-brittle materials belonging to marble may vary depending on the nature of the crushed body, the load-acceleration parameters and the external environment in which the grinding is carried out.

When applied to marble filler in mosaic coatings, abrasive erosion occurs first. It is therefore seen as a process of micro-abrasion of a large number of surfaces of cemented abrasive grains using grinding binders.

The smoothness of the mosaic coating depends mainly on the hardness of the marble filler. The grinding time of the coating at the age of 4-5 days is determined by the grinding time of the marble. Therefore, the search for ways to accelerate the process of grinding marble is a key practical issue.

\section{References}

Bozorboev N., Muxibova N., Salimova I. Technology of construction of floors of various constructions of buildings and constructions. Monograph. Tashkent 2011. "TURON-ISTIQBOL” LLC, 2011.

Bozorboev N., Salimova I. Some problems of flooring technology of buildings and structures. Journal “Architecture. Construction. Design. ” Scientific-practical journal. № 1, Tashkent, 2006.

Gnitsevich E.P., Zavrazhin N.N. Advanced methods of organizing the production of finishing works. M., SI, 1985. -144 pages.

Golubev B.I. Determination of the scope of construction work. Reference book. M., SI, 1991. -63 pages.

Danilov N.N. "Technology of construction production" M., Higher school, 2000.

Zavrazhin N.N. etc. Production of finishing works in construction. (overseas experience). M., SI, 1987. -310 pages.

Zavrazhin N.N. Roofing, waterproofing and flooring. M., SI, 1975 .-- 193 p.

Buzzard N.S. and others. Theoretical foundations of complex mechanization in construction. Kiev, 1982. $-30 \mathrm{p}$.

Lippsmeier G. Construction in a hot climate. Translation from German. M., SI, 1983. -418 p.

New methods of finishing work. Translation from German. M., SI, 1990. -128 pages.

Rumshiskiy L.Z. Mathematical processing of the experimental results. Reference Guide. M., Nauka, 1971. -192 pages.

Spector M.D. "The choice of optimal options for the organization and construction technology", M., SI, 1990.

Tishchenko I.I., Maksimova O.M. Floor arrangement. M., SI, 1975. -24 p.

Khovanskiy G.S. Nomography and its capabilities. Moscow, Nauka, 1977. - 128 p.

Shtol T.M., Evstratov G.I. Construction of buildings and structures in a hot climate. M., V.sh. 1984. -349 p.

Improving construction technology in Uzbekistan (Proceedings of the scientific-practical seminar. October 2931, 2002). 1-2 parts. Tashkent, $2002-245$ pages.

Shvets P.I. and other Reference book of the builder-finisher. Kiev, Budivelnik, 1984. -256 p.

Etin G.E., SigalYa.B. Finishing work in rural construction. Directory. M., SI, 1988. -220 pages.

General production rates of consumption of materials in construction. Collection 16. Floor arrangement. M., SI, 1986.-64 pages.

KMK 3.01.02-00. Safety in construction. T., 2000, -245 b.

ENiR Collection E19. Floor arrangement. Pricelist, M., 1987. -48 pages.

Construction production. Encyclopedia. M., SI, 1995. -464 pages.

Basic terms standardized in the field of standardization, metrology, certification, classification and coding. Russian-Uzbek dictionary of terms. UzME, Tashkent, 1999. - 48 pages.

Construction and scientific and technological progress. Progressive foreign experience. (Collection). M., 1989, no. 12.

Journal "Construction and construction industry" Foreign construction experience. 1997-1999 Moscow 